\title{
Mass Spectrometric Determination of Association Constants of Adenylate Kinase with Two Noncovalent Inhibitors
}

\author{
Jürg M. Daniel, Gregor McCombie, Silke Wendt, and Renato Zenobi \\ Department of Chemistry, Swiss Federal Institute of Technology, ETH, CH-8093 Zürich, Switzerland
}

\begin{abstract}
Noncovalent complexes between chicken muscle adenylate kinase and two inhibitors, $\mathrm{P}^{1}, \mathrm{P}^{4}$ di(adenosine-5')tetraphosphate (Ap4A) and $\mathrm{P}^{1}, \mathrm{P}^{5}$-di(adenosine-5') pentaphosphate (Ap5A), were investigated with electrospray ionization mass spectrometry under non-denaturing conditions. The nonconvalent nature and the specificity of the complexes are demonstrated with a number of control experiments. Titration experiments allowed the association constants for inhibitor binding to be determined. Problems with concentration dependent ion yields are circumvented by a data evaluation method that is insensitive to the overall ionization efficiency. The $\mathrm{K}_{\mathrm{a}}$ values found were $9.0 \times 10^{4} \mathrm{M}^{-1}(\mathrm{Ap} 4 \mathrm{~A})$ and $4.0 \times 10^{7} \mathrm{M}^{-1}(\mathrm{Ap} 5 \mathrm{~A})$, respectively, in very good agreement with available literature data. (J Am Soc Mass Spectrom 2003, 14, 442-448) (c) 2003 American Society for Mass Spectrometry
\end{abstract}

0 oft ionization mass spectrometry (MS), in particular matrix-assisted laser desorption/ionization (MALDI) and electrospray ionization (ESI), is well known for its ability to bring high molecular weight biomolecules into the gase phase and to even preserve noncovalent complexes [1-10]. Besides its established applications, a recurring question concerns the applicability of mass spectrometry to measuring noncovalent interaction strengths [11]. There are different approaches to measure the interaction strengths in the gas phase as well as in the liquid phase. In the former case, the mass spectra should ideally directly represent the solution phase chemistry. Gas-phase methods include cone voltage driven dissociation (called the " $\mathrm{VC}_{50}$ " method) [12, 13], collision-induced dissociation [14, 15], guided ion beam tandem mass spectrometry [16, 17], blackbody infrared radiative dissociation $[18,19]$ and heated capillary dissocation [20,21].

Some mass spectrometric studies have been reported in the literature for the determination of noncovalent interaction strengths. There are three basic methods to determine association constants that are reflective of those in solution: first, it is possible to record "melting curves" by raising the temperature of the analyte solution and to use MS to determine the percentage of intact complexes. Cheng et al. analyzed complementary DNA strands [22] and Fändrich et al. studied the chaperone GimC/prefolding homologue complex [13] with this

Published online April 4, 2003

Address reprint requests to Renato Zenobi, Swiss Federal Institute of Technology, Department of Chemistry, ETH Honggerberg, HCI E 329, Zurich, CH-8093, Switzerland. E-mail: zenobi@org.chem.ethz.ch method. Second, competition experiments can be used to evaluate the stability of noncovalent complexes. In Jørgensen's method [23, 24], the relative intensities of the free host and the different complexes were used, whereas Kempen et al. employed the known concentration of a reference complex to determine the concentration of an unknown complex [25]. Third, a titration of a host with a guest (or vice versa) can be used. In this case, the mass spectrometric signals should accurately represent the concentrations of the species in solution. The titration method is documented in a number of publications, all of them convincingly showing the successful use of mass spectrometry for the quantitative determination of noncovalent binding constants of proteins and small molecules [26-33]. This aspect was the main focus in most previous research; the specificity of the noncovalent interaction was often not verified. However, it is essential to establish that the analyzed complexes are neither gas phase clusters nor the result of unspecific adduct formation in solution. Another, equally important aspect concerns the ionization efficiency of the species appearing in the mass spectra. If a calibration curve is first recorded for one species to evaluate its concentration, the total ionization efficiency must remain the same during a subsequent titration experiment. For some systems this may be true, but often, the total ionization efficiency drops as the titration proceeds. Thus, a measurement that is independent of total ionization efficiency would be preferable.

In an effort to develop soft ionization mass spectrometry into a more accepted and robust method for studying noncovalent interactions quantitatively, we present a method where only the relative signals of a 
protein and a noncovalent protein-inhibitor complex are determined. In other words, a varying overall ionization efficiency will not affect the results. Furthermore, we present a set of control experiments to verify the specificity of the complex and to rule out any unspecific or gas phase adducts. The system studied in this work was adenylate kinase (AK) from chicken muscle and its two noncovalent inhibitors $\mathrm{P}^{1}, \mathrm{P}^{4}$-di(adenosine-5')tetraphosphate (Ap4A) and $\mathrm{P}^{1}, \mathrm{P}^{5}$-di(adenosine-5')pentaphosphate (Ap5A). AK is a phosphotransferase that catalyzes the transfer of the $\gamma$-phosphate group of magnesium-adenosine-triphosphate (MgATP) to adenosine-monophosphate (AMP) and therefore plays an important role in the energy metabolism of cells [34]. There are five major types of AK: AK1 (from cytosols of mammalian or vertebrate muscles, with c, h, p, and $\mathrm{r}$ designating chicken, human, porcine, and rabbit, respectively), AKe (from Escherichia coli), AKy (from yeast), AK2 (from mammalian mitochondrial intermembrane space), and AK3 (from mammalian mitochondrial matrix, specific to GTP instead of ATP). AK1 differs from AKe and AKy in lacking a 30-residue loop near position 132 [35]. In all other aspects of structure and function, AK1 and AKe show high similarities [36]. AK has a molecular weight of 21.6 $\mathrm{kDa}$ and its inhibitors are well studied. It is thus a well-suited model system for the studies presented here.

\section{Experimental Section}

Instrumentation All experiments were conducted on a prototype electrospray orthogonal injection time-offlight mass spectrometer from Agilent (Palo Alto, California, USA). It consists of a commercial atmospheric pressure electrospray interface (Agilent), two skimmers, and an octapol ion guide for collisional cooling. The ions are extracted orthogonally by a pulsed extraction field at a repetition rate of $4 \mathrm{kHz}$. The ions are guided via a single stage reflectron to the detector (ETP Electron Multipliers Pty Ltd., Ermington, Australia). The detector signal is amplified and digitized with a computer (Hewlett Packard, Palo Alto, California, USA) at a sampling frequency of $250 \mathrm{MHz}$. Infusion rates of 3 to $5 \mu \mathrm{l} / \mathrm{min}$ with a pneumatically assisted ESI source ("ion spray") were used. The spray potentials were between 2700 and $3000 \mathrm{~V}$. The source conditions of the instrument were optimized for the transfer of high molecular weight ions and for gentle desolvation conditions by adjusting the different source and transfer potentials. For low energy dissociation experiments the voltage between sampling cone and skimmer was increased, from $32 \mathrm{~V}$ to $140 \mathrm{~V}$, which is sufficient to dissociate noncovalent complexes. Spectra were recorded with a repetition rate of $4 \mathrm{kHz}$ and a couple of 100 '000 spectra were summed and transferred to a PC for further processing.

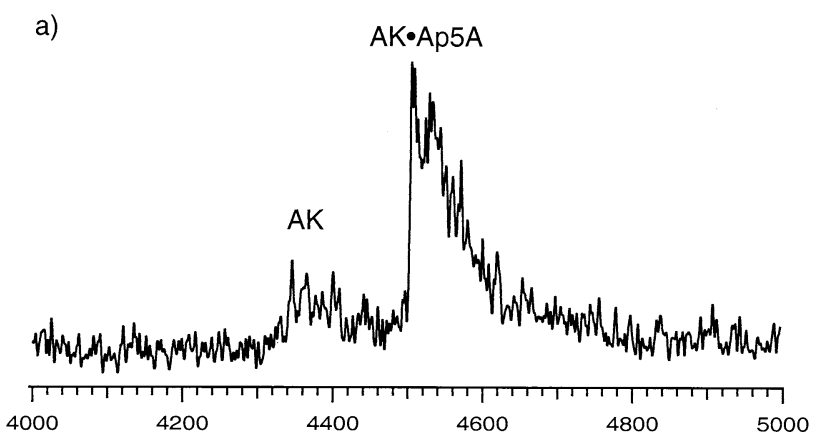

b)

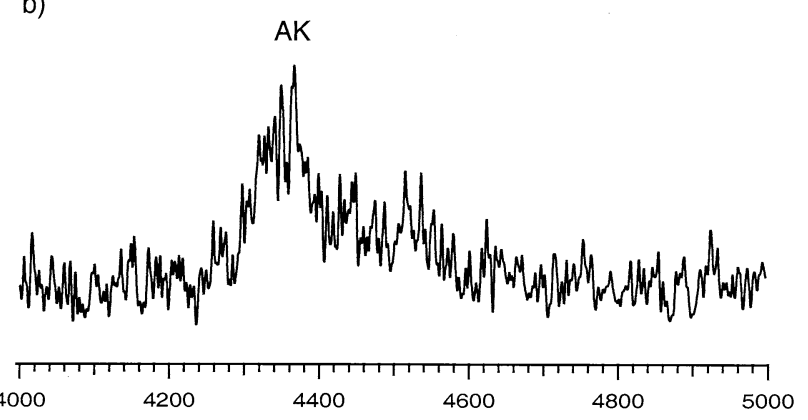

Figure 1. ESI mass spectra (charge state +5) of $10 \mu \mathrm{M} \mathrm{AK}$ and $10 \mu \mathrm{M}$ Ap5A in $50 \mathrm{mM}\left(\mathrm{HNEt}_{3}\right) \mathrm{HCO}_{3}$ with a) soft ionization conditions and $\mathbf{b}$ ) harsher ionization conditions (increased cone voltage) leading to low energy dissociation.

\section{Materials and Methods}

Adenylate kinase $(\mathrm{M}=21689 \mathrm{Da})$ from chicken muscle was obtained from Sigma (St. Louis, MA, USA) and used for the titration experiments without purification. However, even in "essentially salt free" AK samples, a batch dependent amount of magnesium was present. The sample were thus treated by adding EDTA, primarily to allow comparison of our results with literature data. The solvent for all samples was water. $\mathrm{NH}_{4} \mathrm{AcO}$ and $\left(\mathrm{HNEt}_{3}\right) \mathrm{HCO}_{3}$ were used to buffer the proteininhibitor solutions; these are well known for conserving noncovalent interactions in ESI [37]. The titration samples contained between 8.8 and $9.0 \mu \mathrm{M}$ AK (depending on the volume of added inhibitor), 0 to $9.6 \mu \mathrm{M} \mathrm{P}{ }^{1}, \mathrm{P}^{5}-$ di(adenosine-5')pentaphosphate (Ap5A) or 0 to $12 \mu \mathrm{M}$ $\mathrm{P}^{1}, \mathrm{P}^{4}$-di(adenosine-5')tetraphosphate (Ap4A), 50mM $\left(\mathrm{HNEt}_{3}\right) \mathrm{HCO}_{3}$, and $500 \mu \mathrm{M}$ EDTA. Inhibitors were from Fluka (Buchs, Switzerland) and from Sigma (St. Louis, $\mathrm{MO} / \mathrm{USA}$ ), respectively. 8- $\mathrm{N}_{3}$-ATP was obtained from Biolog Life Science Institute, Bremen, Germany.

AK was denatured in four different ways. A solution containing $10 \mu \mathrm{M}$ AK in $10 \mathrm{mM} \mathrm{NH}_{4} \mathrm{AcO}$ buffer was incubated with $50 \% \mathrm{MeOH}$ (HPLC grade) or $5 \% \mathrm{AcOH}$ (reagent grade), prior as well as after adding the $10 \mu \mathrm{M}$ Ap5A. For the low energy dissociation experiments described in Figure 1 (see below), several different solutions were used, including $107 \mu \mathrm{M} \quad \mathrm{AK} / 10 \mu \mathrm{M}$ Ap5A in $50 \mathrm{mM}\left(\mathrm{HNEt}_{3}\right) \mathrm{HCO}_{3}$ buffer and $10 \mu \mathrm{M} \mathrm{AK} /$ $20 \mu \mathrm{M}$ Ap5 A in $5 \mathrm{mM} \mathrm{NH}_{4} \mathrm{AcO}$ buffer. 
AK was covalently modified in its binding pocket according to a slightly adapted method originally published by Olcott [38] and David [39]. $0.3 \mu 15 \mathrm{mM}$ $8-\mathrm{N}_{3}$-ATP in $10 \mathrm{mM} \mathrm{NH}_{4} \mathrm{AcO}, 0.5 \mu \mathrm{l} 20 \mathrm{mM} \mathrm{MgCl}_{2}$, $12 \mu \mathrm{l} 250 \mu \mathrm{M}$ AK in $10 \mathrm{mM} \mathrm{NH}_{4} \mathrm{AcO}$ and $87 \mu \mathrm{l} 50 \mathrm{mM}$ Tris $/ \mathrm{HCl}(\mathrm{pH}=7.2)$ were mixed on ice and incubated for 30 seconds. The solution was exposed to UV radiation at a wavelength of $254 \mathrm{~nm}$ (Westinghouse Electric Corp. Fluorescent \& Vapor Lamp Division, Broomfield, N.J., USA) for 75 seconds. Another $0.3 \mu \mathrm{l}$ $5 \mathrm{mM} 8-\mathrm{N}_{3}$-ATP in $10 \mathrm{mM} \mathrm{NH}_{4} \mathrm{AcO}$ was added and again exposed to the UV radiation for 75 seconds. The Tris/HCl buffer was exchanged with a NAP-5 gel permeation column (Pharmacia Biotec AB, Sweden) to $10 \mathrm{mM} \mathrm{NH}_{4} \mathrm{AcO}$. The reaction was incomplete, but the activity of the treated AK sample was probed by an essay described by Wallimann et al. [40] and was found to be reduced by $25 \% \pm 5 \%$. The mass of the modified AK was $22259 \mathrm{Da}$.

Data Evaluation Equations 1 through 3 describe the complex formation of AK with its inhibitor ApXA:

$$
\begin{aligned}
& K_{a}=\frac{[A K \cdot A p X A]}{[A K] \times[A p X A]} \\
& {[A K]_{0}=[A K]+[A K \cdot A p X A]}
\end{aligned}
$$

$$
[A p X A]_{0}=[A p X A]+[A K \cdot A p X A]
$$

where $K_{a}$ is the association constant, $[\mathrm{AK}]$ the concentration of the bare protein, [ApXA] the concentration of the inhibitor and $[\mathrm{AK} \cdot \mathrm{ApXA}]$ the concentration of the complex. " 0 " denotes the total concentration of a given species. Experimentally, we measure the concentration ratio of the complex and the bare protein, which is called R below:

$$
R=\frac{[A K \cdot A p X A]}{[A K]}
$$

These equations can be solved for $K_{a}$ for known values of $[\mathrm{AK}]_{0}$ and $[\mathrm{ApXA}]_{0}$ to yield eq 5 :

$$
K_{a}=\frac{R^{2}+R}{[A p X A]_{0} \times(1+R)-[A K]_{0} \times R}
$$

A more robust, global data evaluation that takes into account all data points can be achieved by a least squares fit of the experimental $R$ vs. known [ApXA] values to an expression which is obtained by solving the above equations for $R$. This yields eq 6 , where $K_{a}$ is the only adjustable parameter.

$$
R=\frac{1}{2}\left(-1-K_{a} \times[A K]_{0}+K_{a} \times[A p X A]_{0}+\sqrt{4 \times K_{a} \times[A p X A]_{0}+\left(K_{a} \times[A p X A]_{0}-K_{a} \times[A K]_{0}-1\right)^{2}}\right)
$$

Particularly for statistical error analysis, the fit described in eq 6 is preferable to a Scatchard plot (see, for example [32]) or other forms of data linearization that are used for graphical evaluation of protein inhibition. A similar approach as the one described here was chosen by Greig et al. [26] who used a fit to a second order polynomial to determine two dissociaton constants of a BSA-oligonulecotide complex.

In the approach described here, the ratio $R$ of peak areas for the $[\mathrm{AK}]$ and $[\mathrm{AK} \cdot \mathrm{ApXA}]$ signals is used to determine the association constant. A good baseline correction method is important to obtain reliable results, in particular when one of the peaks is hardly visible. Different baseline correction methods were therefore tested. In the simplest approach, a constant value was subtracted from the data. In a more refined method, a line was fitted to the baseline allowing the correction of a sloping baseline. In the third method, a linear baseline was calculated for each peak, allowing for different slopes in the baseline. In the most sophisticated method, an arbitrary mathematical form of the baseline was allowed. The differences between these methods were found to be negligible. Therefore the simplest baseline correction method was used throughout.
Each titration point was measured five times. The +5 charge state of the bare protein and the complex were integrated. Other detectable charge states had negligible signal intensities. The ratio $\mathrm{R}$ was calculated for each spectrum. A least square fit was performed using equation 5 with $K_{a}$ as the fitting parameter for the titration experiment.

\section{Results and Discussion}

For analysis of large noncovalent complexes, suitable conditions must be found where desolvation is sufficiently complete to allow mass resolution of all different species, but where the noncovalent complex is not destroyed. This compromise is responsible for the fairly low S/N ratio, which was found to drop even further with increasing inhibitor concentration. Figure 2 shows mass spectra of $8.8 \mu \mathrm{M}$ AK with $8 \mu \mathrm{M}$ Ap4A (Trace a) and Ap5A (Trace b), respectively. The observed peaks are all quite broad, probably due to an incomplete desolvation leading to water and buffer adducts. However, the signals of free AK and of the complexes are clearly resolved. Dependent on the sample batch, a second, less abundant peak for AK and for AK·ApXA was detected in some of the spectra. It could not be 
a)

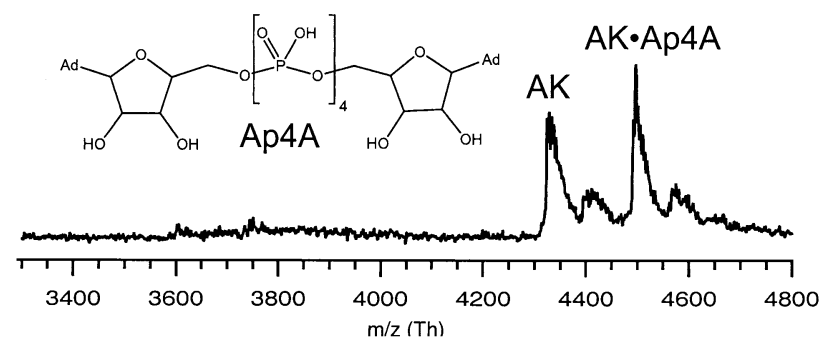

b)

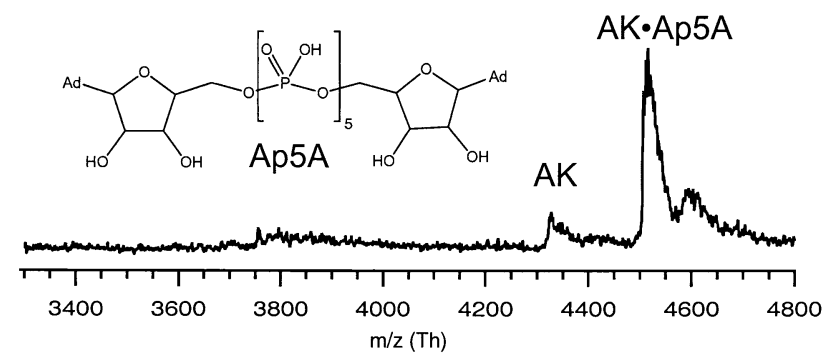

Figure 2. Spectrum of $8.8 \mu \mathrm{M} \mathrm{AK}(+5$ charge state) with a) $8 \mu \mathrm{M}$ Ap4A and b) $8 \mu \mathrm{M}$ Ap5A in $50 \mathrm{mM}\left(\mathrm{HNEt}_{3}\right) \mathrm{HCO}_{3}$. The ionization and the desolvation are very soft, leading to broad peaks. Many salt and buffer adducts are observed. In the insets Ap4A respectively Ap5A is shown, whereas Ad denotes for adenine.

unambiguously identified, but we assume it to be due to a contamination from a sequence variant of AK. Since these peaks originate from an AK variant of comparable activity, we included them in the evaluation of the titration experiments as well.

If a signal at the mass of a complex is detected by mass spectrometry, it does not automatically imply that the complex is indeed noncovalent and specific. Therefore we performed a number of control experiments to prove the specificity and the noncovalent nature of the suggested interaction. Figure 1 shows spectra of AK with the inhibitor Ap5A at physiological pH. Trace (a) was recorded with soft ionization and desolvation conditions preserving the noncovalent complex, whereas trace (b) represents harsher conditions (increased cone - skimmer voltage) leading to low energy dissociation of the complex. This data shows the +5 charge state and was recorded using $10 \mu \mathrm{M}$ AK and 10 $\mu \mathrm{M}$ Ap5 A in $50 \mathrm{mM}\left(\mathrm{HNEt}_{3}\right) \mathrm{HCO}_{3}$. Identical behavior was found for other solution conditions, e.g., $10 \mu \mathrm{M}$ AK, $20 \mu \mathrm{M}$ Ap5A in $5 \mathrm{mM} \mathrm{NH}_{4} \mathrm{AcO}$. The complex always disappeared under harsher interface conditions, while the protein itself remained intact. We can thus safely assume that this complex is of noncovalent nature. Further control experiments included methanol or acetic acid induced denaturation of AK both prior to and after adding Ap5A to the solution. An intact tertiary structure of the protein is needed to form and maintain the noncovalent complex. Upon denaturation, no complexes could be observed (data not shown), giving additional strong evidence for its specificity.

Finally, it should be confirmed that the inhibitor binds at the active site of the protein. Therefore, AK was covalently modified as outlined in the experimental section. In brief, the active site is blocked by covalently bound ATP mimic. The resulting sample contained both modified and unmodified AK which could be differenciated due to their different mass. Figure 3 shows the mass spectrum of this modified AK sample in the presence of Ap5A at physiological $\mathrm{pH}$. Almost no inhibitor binding of the modified AK is observed, suggesting that the inhibitor Ap5A binds in the active site of the unmodified protein only. The results of all control experiments are fully consistent with specific noncovalent inhibitor binding in the active site of the

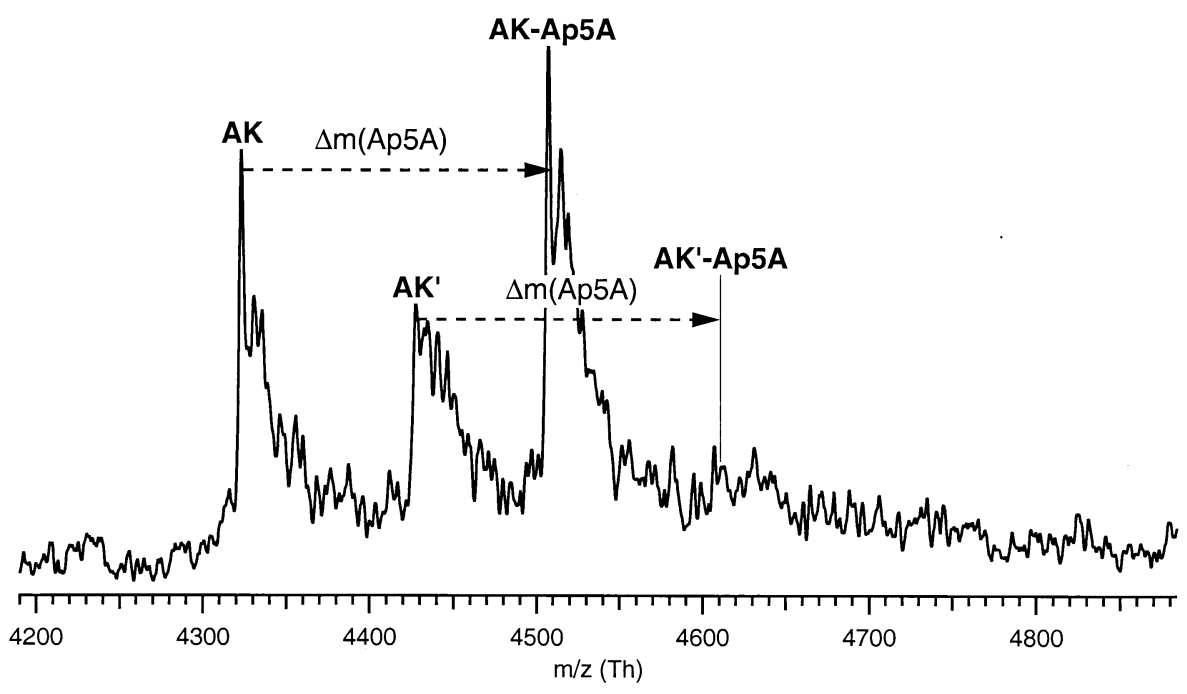

Figure 3. Spectrum of the reaction mixture (10 $\mu \mathrm{M}$ total protein) of AK and covalently modified AK (AK') with $10 \mu \mathrm{M}$ of Ap5A (with respect to the total concentration of $\mathrm{AK}$ and $\mathrm{AK}$ ) in $50 \mathrm{mM}$ $\left(\mathrm{HNEt}_{3}\right) \mathrm{HCO}_{3}$. Almost no binding to $\mathrm{AK}^{\prime}$ is observed, suggesting that the inhibitor binds in the binding pocket of the protein. 


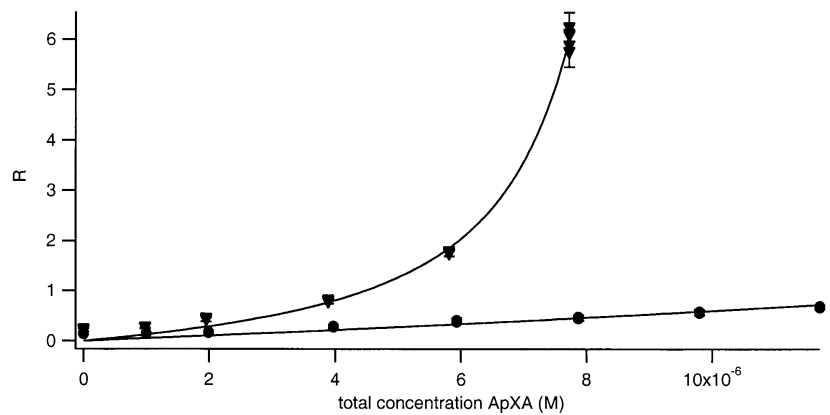

Figure 4. Result of the titration experiments of AK with Ap5A (filled inverted triangle, $\mathrm{Ka}=4.0 \times 10^{7} \mathrm{M}^{-1}$ ) and AK with Ap4A (filled circle, $\mathrm{Ka}=9.0 \times 10^{4} \mathrm{M}^{-1}$ ). The lines are the fitted data with eq 6.

protein. The second inhibitor, Ap4A, is much less well studied than Ap5A. For example, no crystal structure data exist for AK-Ap4A complexes. For the present investigation, we assume that Ap4A also froms a similar complex with AK, as suggested by other studies [41, 42].

For the determination of solution phase binding constants by mass spectrometry, it is necessary that the experiment satisfies two conditions. First, the ionization efficiency of the protein and the complex should be equal. Second, the noncovalent complex must survive the ionization process, the transfer into the high vacuum, and the acceleration in the TOF instrument. The first condition is probably fulfilled in the present case: identical charge distributions were found for the bare protein and the protein-inhibitor complexes. Also, the tertiary structure and the mass of the bare protein and the complex are similar. During the titration experiments, we found the total ionization efficiency to decrease with increasing concentration of the inhibitor. Since we only determine the ratio of the complex and the bare protein, this has no effect on the titration results as long as the assumption of equal ionization efficiencies for both species holds. The second condition should be satisfied, too. For this particular case, electrostatic and dipolar interactions are involved in the stabilization of the complex $[43,44]$ forces that are expected to increase upon solvent removal (unlike hydrophobic interactions that will decrease or even vanish in the gas phase).
The association constants for the AK·ApXA system were determined as described in the "Data Evaluation" section. The experimentally obtained R-values are plotted against the total inhibitor concentrations used for the titration. In Figure 4, this plot is shown for both noncovalent inhibitors. The lines represent a fit for the association constant obtained with help of eq 6 . The association constant for AK and Ap5A is $\mathrm{K}_{\mathrm{a}}=4.0 \times 10^{7}$ $\mathrm{M}^{-1}$, for AK and Ap4A $K_{a}=9.0 \times 10^{4} \mathrm{M}^{-1}$. Because the $K_{a}$ value for this particular system depends on the magnesium concentration of the solution, any remaining magnesium was masked by adding an excess of EDTA. The relative standard deviations for the titration points were between $1.6 \%$ and $5.0 \%$. The confidence interval for $K_{a}$ is difficult to estimate, but it will most probably be less than one order of magnitude. In Table 1 , the values obtained experimentally are compared to data published in the literature. Values determined by mass spectrometry for AK from chicken muscle lie in the same range as literature values for different species and are therefore in very good agreement. These results also validate our control experiments and the conditions for the titration. It shows that the selected control experiments are useful and that the postulated conditions are justifiable.

\section{Conclusions}

We have shown the successful determination of solution phase association constants of noncovalent proteininhibitor complexes by ESI mass spectrometry. Mass spectrometry has great potential for becoming a widely used method in this area due to its sensitivity and speed. This method allows screening of drug libraries with respect to their association constants to a target protein. In this case, control experiments to confirm the noncovalent nature and the specificity of the complexes are only necessary to prevent overestimations of association constants due to unspecific aggregation or covalent binding. For "misses," such controls will usually not be necessary. Furthermore, the present analysis assumes that all complexes formed in solution survive in the mass spectrometer for the timescale of the measurement, and that the ionization efficiency of the bare target protein and of the protein-inhibitor complex are equal. These assumptions are true for the present sys-

Table 1. Comparison of the association constants measured and published in the literature

\begin{tabular}{llrl}
\hline Complex & \multicolumn{1}{c}{ Species } & $\mathrm{K}_{\mathrm{a}}\left[\mathrm{M}^{-1}\right]$ & Reference \\
\hline \hline AK1-Ap4A & Chicken muscle & $9.0 \times 10^{4}$ & This work \\
AKe-MgAp4A & Escherichia coli & $2.3 \times 10^{4}$ & Reinstein et al. [34] \\
AKe-Ap4A & Escherichia coli & $7.7 \times 10^{4}$ & Reinstein et al. [34] \\
AK1-MgAp4A & Pig muscle & $9.1 \times 10^{4}$ & Feldhaus et al. [42] \\
AK1-Ap5A & Chicken muscle & $4.0 \times 10^{7}$ & This work \\
AKe-MgAp5A & Escherichia coli & $6.7 \times 10^{7}$ & Reinstein et al. [34] \\
AKe-AP5A & Escherichia coli & $1.0 \times 10^{7}$ & Reinstein et al. [34] \\
AK1-MgAp5A & Rabbit muscle & $2.8-5.0 \times 10^{8}$ & Lienhard et al. [45] \\
AK1-MgAp5A & Pig muscle & $3.4 \times 10^{7}$ & Feldhaus et al. [42] \\
\hline
\end{tabular}


tem, but must be validated when investigating unknown systems.

\section{Acknowledgments}

The authors thank Sebastian D. Friess for helpful discussions and for carefully proofreading the manuscript. This work was supported by the Swiss National Science Foundation, Grant No. 2000-058861.

\section{References}

1. Siuzdak, G. The emergence of mass spectrometry in biochemical research. Proc. Natl. Acad. Sci. U.S.A. 1994, 91, 1129011297.

2. Smith, R. D.; Bruce, J. E.; Wu, Q.; Lei, Q. P. New mass spectrometric methods for the study of noncovalent associations of biopolymers. Chem. Soc. Rev. 1997, 26, 191-202.

3. Loo, J. A. Studying noncovalent protein complexes by ESI MS. Mass Spectrom. Rev. 1997, 16, 1-23.

4. Pramanik, B. N.; Bartner, P. L.; Mirza, U. A.; Liu, Y.-H.; Ganguly, A. K. ESI MS for the Study of Non-covalent Complexes: an Emerging Technology. J. Mass Spectrom. 1998, 33, 911-920.

5. Hillenkamp, F. New Methods for the Study of Biomolecular Complexes. Kluwer Academic Publishers: Dordrecht, The Netherlands, 1998.

6. Farmer, T. B.; Caprioli, R. M. Determination of protein-protein interactions by matrix-assisted laser desorption/ionization mass spectrometry. J. Mass Spectrom, 1998, 33, 697-704.

7. Winston, R. L.; Fitzgerald, M. C. Mass Spectrometry as a readout of Protein structure and Function. Mass Spectrom. Rev. 1997, 16, 165-179.

8. Przybylski, M.; Glocker, M. O. Electrospray Mass Spectrometry of Biomacromolecular Complexes with Noncovalent Interactions-New Analytical Perspectives for Supramolecular Chemistry and Molecular Recognition Processes. Angew. Chem.-Int. Edit. Engl. 1996, 35, 807-826.

9. Woods, A. S.; Buchsbaum, J. C.; Worrall, T. A.; Berg, J. M.; Cotter, R. J. Matrix-Assisted Laser Desorption/Ionization of Noncovalently Bound Compounds. Anal. Chem. 1995, 67, 4462-4465.

10. Strupat, K.; Sagi, D.; Bönisch, H.; Schäfer, G.; Peter-Katalinic, J. Oligomerization and Substrate Binding Studies of the Adenylate Kinase from Sulfolobus acidocaldarius by Matrix-assisted Laser Desorption/Ionization Mass Spectrometry. Analyst 2000, 125, 563-567.

11. Daniel, J. M.; Friess, S. D.; Rajagopalan, S.; Wendt, S.; Zenobi, R. Quantitative determination of noncovalent binding interactions using soft ionization mass spectrometry. Int. J. of Mass Spectrom. 2002, 216, 1-27.

12. Rogniaux, H.; Van Dorsselaer, A.; Barth, P.; Biellmann, J. F.; Barbanton, J.; van Zandt, M.; Chevrier, B.; Howard, E.; Mitschler, A.; Potier, N.; Urzhumtseva, L.; Moras, D.; Podjarny, A. Binding of Aldose Reductase Inhibitors: Correlation of Crystallographic and Mass Spectrometric Studies. J. Am. Soc. Mass Spectrom. 1999, 10, 635-647.

13. Fändrich, M.; Tito, M. A.; Leroux, M. R.; Rostom, A. A.; Hartl, F. U.; Dobson, C. M.; Robinson, C. V. Observation of the noncovalent assembly and disassembly pathways of the chaperone complex MtGimC by mass spectrometry. Proc. Natl. Acad. Sci. U.S.A. 2000, 97, 14151-14155.

14. Nesatyy, V. J. Gas-phase binding of non-covalent protein complexes between bovine pacreatic trypsin inhibitor and its target enzymes studied by ESI tandem MS. J. Mass Spectrom. 2001, 36, 950-959.
15. Jørgensen, T. J. D.; Delforge, D.; Remacle, J.; Bojesen, G.; Roepstorff, P. Collision-induced dissociation of noncovalent complexes between vancomycin antibiotics and peptide ligand stereoisomers: evidence for molecular recognition in the gas phase. Int. J. of Mass Spectrom. 1999, 188, 63-85.

16. Rodgers, M. T.; Armentrout, P. B. Noncovalent Metal-Ligand Bond Energies as studied by Threshold Collision-induced Dissociation. Mass Spectrom. Rev. 2000, 19, 215-247.

17. Rodgers, M. T.; Armentrout, P. B. Noncovalent Interactions of Nucleic Acid Bases (Uracil, Thymine, and Adenine) with Alkali Metal Ions. Threshold Collision-Induced Dissociation and Theoretical Studies. J. Am. Chem. Soc. 2000, 122, 85488558.

18. Strittmatter, E. F.; Schnier, P. D.; Klassen, J. S.; Williams, E. R. Dissociation energies of deoxyribose nucleotide dimer anions measured using blackbody infrared radiative dissociation. J. Am. Soc. Mass Spectrom. 1999, 10, 1095-1104.

19. Schnier, P. D.; Klassen, J. S.; Strittmatter, E. F.; Williams, E. R. Activation Energies for Dissociation of Double Strand Oligonucleotide Anions: Evidence for Watson-Crick Base Pairing in Vacuo. J. Am. Chem. Soc. 1998, 120, 9605-9613.

20. Garcia, B. A.; Ramirez, J.; Wong, S.; Lebrilla, C. B. Thermal dissociation of protonated cyclodextrin-amino acid complexes in the gas phase. Int. J. of Mass Spectrom. 2001, 210/211, 215-222.

21. He, F.; Ramirez, J.; Garcia, B. A.; Lebrilla, C. B. Differentially heated capillary for thermal dissociation of noncovalently bound complexes produced by electrospray ionization. Int. J. of Mass Spectrom. 1999, 182, 261-273.

22. Cheng, X. H.; Gao, Q. Y.; Smith, R. D.; Jung, K.-E.; Switzer, C. Comparison of 3',5'- and 2',5'-linked DNA duplex stabilities by electrospray ionization mass spectrometry. Chem. Commun. 1996, 747-748.

23. Jørgensen, T. J. D.; Staroske, T.; Roepstorff, P.; Williams, D. H.; Heck, A. J. R. Subtle Differences in molecular recognition between modified glycopeptide antibiotics and bacterial receptor peptides identified by ESI MS. J. Chem. Soc. Perkin Trans. 2 1999, 1859-1863.

24. Jørgensen, T. J. D.; Roepstorff, P.; Heck, A. J. R. Direct Determination of Solution Binding Constants for Noncovalent Complexes between Bacterial Cell Wall Peptide Analogues and Vancomycin Group Antibiotics by Electrospray Ionization Mass Spectrometry. Anal. Chem. 1998, 70, 4427-4432.

25. Kempen, E. C.; Brodbelt, J. S. A Method for the Determination of Binding Constants by ESI MS. Anal. Chem. 2000, 72, 54115416.

26. Greig, M. J.; Gaus, H.-J.; Cummins, L. L.; Sasmor, H.; Griffey, R. H. Measurement of Macromolecular Binding Using Electrospray Mass Spectrometry. Determination of Dissociation Constants for Oligonucleotide-Serum Albumin Complexes. J. Am. Chem. Soc. 1995, 117, 10765-10766.

27. Griffey, R. H.; Hofstadler, S. A.; Sannes-Lowery, K. A.; Ecker, D. J.; Crooke, S. T. Determinants of aminoglycoside-binding specificity for rRNA by using mass spectrometry. Proc. Natl. Acad. Sci. U.S.A. 1999, 96, 10129-10133.

28. Eckart, K.; Spiess, J. Electrospray Ionization Mass Spectrometry of Biotin Binding Streptavidin. J. Am. Soc. Mass Spectrom. 1995, 6, 912-919.

29. Carte, N.; Legendre, F.; Leize, E.; Potier, N.; Reeder, F.; Chottard, J.-C.; Van Dorsselaer, A. Determination by Electrospray Mass Spectrometry of the Outersphere Association Constants of DNA/Platinum Complexes Using 20-mer Oligonucleotides and ([Pt(NH3)4]2+, 2Cl-) or ([Pt(py)4]2+, 2Cl-). Anal. Biochem. 2000, 284, 77-86.

30. Ayed, A.; Krutchinsky, A. N.; Ens, W.; Standing, K. G.; Duckworth, H. W. Quantitative Evaluation of Protein-Protein and Ligand-Protein Equilibria of a Large Allosteric Enzyme by 
Electrospray Ionization Time-of-flight Mass Spectrometry. Rapid Commun. Mass Spectrom. 1998, 12, 339-344.

31. Lim, H.-K.; Hsieh, Y. L.; Ganem, B.; Henion, J. Recognition of Cell-wall Peptide Ligands by Vancomycin Group Antibiotics: Studies Using Ion Spray Mass Spectrometry. J. Mass Spectrom. 1995, 30, 708-714.

32. Loo, J. A.; Hu, P.; McConnell, P.; Mueller, W. T. A Study of Src SH2 Domain Protein-Phosphopeptide Binding Interactions by Electrospray Ionization Mass Spectrometry. J. Am. Soc. Mass Spectrom. 1997, 8, 234-243.

33. Sannes-Lowery, K. A.; Griffey, R. H.; Hofstadler, S. A. Measuring Dissociation Constants of RNA and Aminoglycoside Antibiotics by Electrospray Ionization Mass Spectrometry. Anal. Biochem. 2000, 280, 264-271.

34. Reinstein, J.; Vetter, I. R.; Schlichting, I.; Rösch, R.; Wittinghofer, A.; Goody, R. S. Fluorescence and NMR Investigations on the Ligand Binding Properties of Adenylate Kinase. Biochemistry 1990, 29, 7440-7450.

35. Haase, G. H. W.; Brune, M.; Reinstein, J.; Pai, E. F.; Pingoud, A.; Wittinghofer, A. Adenylate Kinase from Thermosensitive Escherichia coli Strains. J. Mol. Biol. 1989, 207, 151-162.

36. Dahnke, T.; Tsai, M.-D. Mechanism of Adenylate Kinase. Structural and Functional Roles of the Conserved Arginine-97 and Arginine-132. J. Biol. Chem. 1994, 269, 8075-8081.

37. Lemaire, D.; Marie, G.; Serani, L.; Laprévote, O. Stabilization of Gase-Phase Noncovalent Macromolecular Complexes in Electrospray Mass Spectrometry Using Aqueous Triethylammonium Bicarbonate Buffer. Anal. Chem. 2001, 73, 1699-1706.
38. Olcott, M. C.; Bradley, M. L.; Haley, B. E. Photoaffinity Labeling of Kinase with 2-Azido and 8-Azidoadenosine Triphosphate: Identification of Two Peptides from the ATPBinding-Domain. Biochemistry 1994, 33, 11935-11941.

39. David, S. S.; Haley, B. E. ATP Nucleotidylation of Creatine Kinase. Biochemistry 1999, 38, 8492-8500.

40. Wallimann, T.; Turner, D. C.; Eppenberger, H. M. Localization of creatine kinase isoenzymes in myofibrils. I. Chicken skeletal muscle. J. Cell Biol. 1977, 75, 297-317.

41. Purich, D. L.; Fromm, H. J. Inihibition of Rabbit Skeletal Muscle Adenylate Kinase by the Transition State Analogue P1,P4-di(adenosine-5')tetraphophate. Biochim. Biophys. Acta 1972, 276, 563-567.

42. Feldhaus, P.; Fröhlich, T.; Goody, R. S.; Isakov, M.; Schirmer, R. H. Synthetic inhibitors of adenylate kinases in the assays for ATPases and phosphokinases. Eur. J. Biochem. 1975, 57, 197204.

43. Shi, Z.; Byeon, I. L.; Jiang, R.; Tsai, M.-D. Mechanism of Adenylate Kinase. What Can Be Learned from a Mutant Enzyme with Minor Perturbation in Kinetic Parameters? Biochemistry 1993, 32, 6450-6458.

44. Müller, C. W.; Schulz, G. E. Structure of the Complex Between Adenylate Kinase from Escheriachia coli and the Inhibitor Ap5A Refined at 1.9A Resolution. J. Mol. Biol. 1992, 224, 159-177.

45. Lienhard, G. E.; Secemski, I. I. P1,P5-Di(adenosine-5')pentaphosphate, a Potent Multisubstrate Inhibitor of Adenylate Kinase. J. Biol. Chem. 1973, 248, 1121-1123. 